Marketplace is provided as a service to readers using text and images from the manufacturer, supplier or distributor and does not imply endorsement by Vital. Normal and prudent research should be exercised before purchase or use of any product mentioned.

\section{Perfect patient info}

Ensuring your patients make the right dental care decision is a crucial part in the development of a treatment plan and the information given to patients determines what treatments they choose. Straumann understands the obstacles practitioners face when trying to keep patients informed about treatments and offers a variety of patient literature explaining all treatment options available through the Straumann Dental Implant System.

Patient literature placed in your patient area or given when suggesting treatment plans can be very reassuring to patients and can make it increasingly likely that they will choose the right option for them. For FREE Straumann patient literature, please call 01825760686.

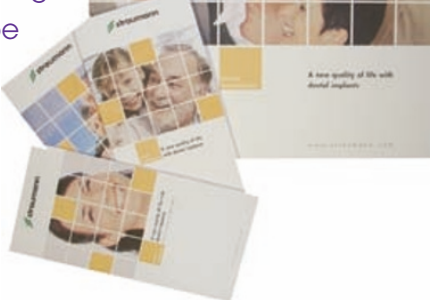

\section{Design your own uniform!}

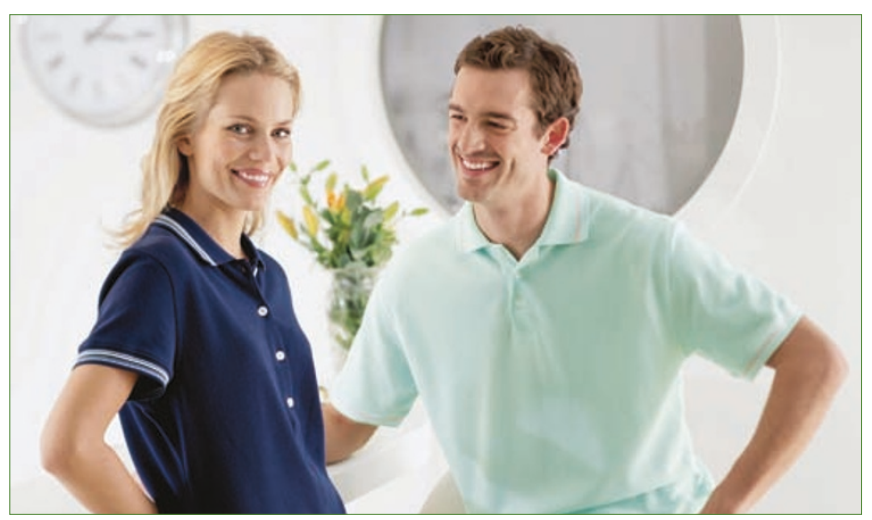

Need another pocket? Prefer a zip fastening? Fancy a wackier colour? Now's your chance to design your uniform just the way you would like it.

Kent Express has teamed up with Hejco to launch a 'Design Your Own Uniform' competition and if you win first prize, Hejco will produce your design for you and your team up to a maximum team size of 15 . The first, second and third prize winners will also receive a Red Letter Day experience - international Americas Cup class sailing or a tour of London by helicopter are just two of the experiences available.

You can design either a male or a female uniform and entries close on 31 June 2006. To enter, submit your design on the sheets provided in the 'Design Your Own Uniform' competition pack and include any additional sketches and notes on details like material, stitching or pockets. All winners will be notified by 31 July 2006 and prizes will be delivered by 30 November. To obtain your competition pack, call Kent Express on 01634 878787. Good luck and happy designing!

\title{
Achieve a diamond finish
}

Highly smooth composite surfaces reduce plaque build-up and discolouration and consequently restorations look better and last longer. Trycare's Dentatus 3-2-1-Go finishing diamonds are specifically designed for contouring, finishing and polishing composite materials to perfection.

Supplied in a range of 10 patterns in three grain sizes, Dentatus 3-2-1-Go finishing diamonds

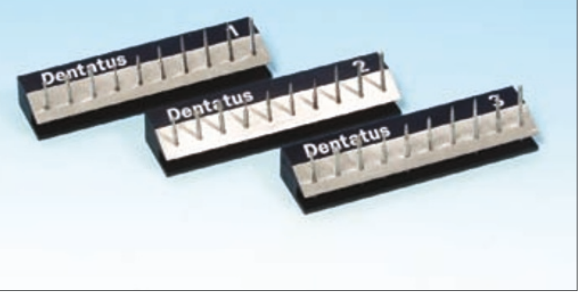
are colour coded with laser-marked shanks for easy identification. Each is constructed on a stainless steel shaft to the highest precision. The grain sizes start with $50 \mu \mathrm{m}$ fine diamonds, for removal of overhangs and basic contouring, then $30 \mu \mathrm{m}$ extra fine diamonds for fine contouring and finishing. Finally there are $15 \mu \mathrm{m}$ extra fine diamonds designed for polishing. Available separately in blister packed refills of three, all 10 patterns are also available as an assortment on an appropriately marked stand. For more information please call Trycare Ltd on 01274881044 or email mail@trycare.co.uk.

\section{Poultry flavoured toothpaste}

Poultry toothpaste is just one of the exciting new product lines offered in Dent-O-Care's latest mail order catalogue for patients - although it does feature in the animal oral health page for pet owners! Additions to patient oral care products include homeopathic remedies, a magnetised cordless water jet kit and natural ingredient toothpaste and mouthwash, among many others.

First launched 15 years ago, the 32-page 'Complete Oral Care' booklet and its complementary website continue to offer

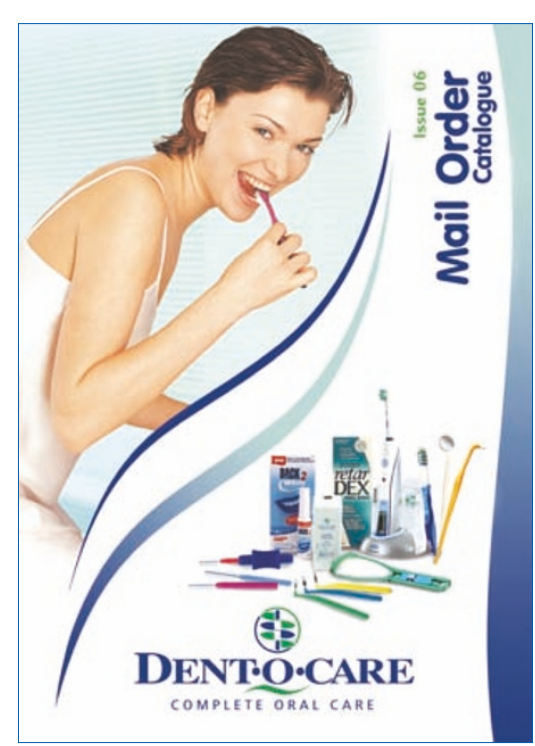

patients 24-hour access to recommended products between appointments. The booklet is free of charge to all dental professionals and includes contact details for the British Dental Health Foundation and British Homeopathic Dental Association, ensuring professional and impartial patient advice. To browse the latest issue and order unlimited free copies, Freephone 08009801517. 